\title{
Effect of diurnal changes on the auditory working memory in individuals with normal hearing
}

\author{
Praveen Prakash, Chandana Shivaiah, Abishek Umashankar and Prashanth Prabhu * \\ Department of Audiology All India Institute of Speech and Hearing Mysuru, Naimisham Campus, Road No.3 TK \\ Layout, Manasagangotri, Mysuru Karnataka 570006, India. \\ * Correspondence: prashanth.audio@gmail.com; Tel.: +918904353390 \\ Received: 27 July 2021; Accepted: 21 October 2021; Published: 8 December 2021 \\ Edited by: Wael Mohamed (Menoufia Medical School Shebin El Kom, Egypt) \\ Reviewed by: Maralgua Och (Mongolian National University of Medical Sciences, Mongolia); Lilach Soreq \\ (University College London, UK); MS Zobaer (The University of Texas Health Science Center at Houston, USA) \\ https://doi.org/10.31117/neuroscirn.v4i4.110
}

\begin{abstract}
The human circadian rhythmicity is an internal biological clock mechanism that enables them to effectively perform tasks during a particular time of the day, due to which they exhibit diurnal effects. The morningness-eveningness questionnaire classifies individuals as definitely morning, moderately morning, intermediate, moderately evening, and definitely evening type individuals based on their active performance during different times of the day. Literature show variations in visual, memory, audition, and other cognitive tasks throughout the day in every individual. The current study aimed to document the diurnal effects on auditory working memory, a phenomenon crucial for learning and academic outcomes and holds its role in various clinical and research fields. Thirty-two participants were enrolled ( 21 females and 11 males) and were classified based on the morningness-eveningness questionnaire. The Auditory Working Memory tests were carried out during the morning and evening for all the participants. Based on a parametric paired ttest, results reveal no significant differences between morning time and evening time across moderately morning, intermediate, and moderately evening groups implying that working memory is a higher-order function that shows no or negligible diurnal effects, unlike other lower-order functions like temporal processing of auditory signals.
\end{abstract}

Keywords: Working memory; diurnal effects; higher-order functions;

(C2021 by Prakash et al. for use and distribution in accord with the Creative Commons Attribution (CC BY-NC 4.0) license (https://creativecommons.org/licenses/by-nc/4.0/), which permits unrestricted non-commercial use, distribution, and reproduction in any medium, provided the original author and source are credited.

\subsection{INTRODUCTION}

Chrono-psychologists define the diurnal effect as the time of the day that an individual feels most active. The variations in the circadian rhythmicity in these individuals cause them to be active at a particular time of the day. The circadian rhythmicity is an intracellularly balanced attribute that happens at the genetic level of each organism that helps it to follow an internal biological clock mechanism (Katzenberg et al., 1998).
This biological clock is associated with the homeostatic process that controls the sleep-wake cycles in humans (Schmidt et al., 2007). The human Circadian rhythms are physical, mental and behavioural changes that follow a 24-hour cycle. It naturally responds to light and dark and other external components like environmental temperature, the intensity of environmental light, the presence of other animals, stress, and even health conditions. In humans, it is well accepted that the 
suprachiasmatic nucleus (SCN) of the hypothalamus, also known as the circadian pacemaker or the maser clock, has a significant influence on sleep-wake cycles (Revell \& Eastman, 2005). Based on this rhythmicity, individuals tend to develop a morning and evening effect over the activities they perform, typically the diurnal effect. This diurnal effect creates an active performance at a particular time of the day and results in an inverse reduction in performance during the other part of the day (Kerkhof, 1985). However, this might not be evident in every individual to the same extent. An individual can be a morning type, intermediate type, or an evening type, which could be determined by the "MorningnessEveningness questionnaire", given by Horne and Ostberg (1976) -consisting of 19 questions, this questionnaire can be used to rate the preferences of individuals for their physical and mental activities and alertness (Horne \& Ostberg, 1976). After scoring for the total items, it categorizes individuals into five categories; definitely morning, moderately morning, intermediate (those who do not exhibit either significant morning nor evening preferences), moderately evening, and definitely evening.

Literature shows that the diurnal effect can influence various tasks such as auditory perception, visual perception, memory, other cognitive functions, and even physical activities. In the context of audition, diurnal effects on the auditory related functions have been documented with subjective as well as objective evidence. With respect to auditory electrophysiological studies, a study conducted by Huang et al. (2005) on the changes in Late latency response and $\mathrm{P} 300$ responses in the morning and evening-type individuals revealed an increased amplitude and shorter latency for morningtype individuals when tested during the morning. Similarly, evening-type individuals were noted increased amplitude and shorter latencies when tested during the evening. Kerkhof et al. (1980), in their study, revealed that the N1-P2 amplitude was enhanced in morning type individuals during morning and evening type individuals during the evening. A similar article by Kerkhof (1982) on the event-related potentials and auditory signal detection task in morning and evening individuals revealed positive diurnal effects for auditory signal detection, N115 component, P190 component where morning individuals performed better in the morning with the performance monotonically decreasing over the day and evening individuals showing improved performance during the evening. However, no diurnal effects were seen for P450 and slow-wave components.
Recent psychoacoustical studies by Nikhil et al. (2018) and Prakash et al. (2021) revealed significant diurnal effects in differential sensitivity and auditory temporal processing abilities in individuals with normal hearing. However, in both the studies, there were no significant diurnal changes observed in individuals who belonged to the intermediate category.

Apart from the psychoacoustical bases of auditory perception, another essential component is the auditory working memory. The term 'working memory' refers to the temporary storage of information, connected with the performance of other cognitive tasks such as reading, problem-solving, or learning, which serves as an encoding of the information in the form of stimuli and retrieval of information from previously stored material (Alloway et al., 2009; Vuontela et al., 2003). Initially, it was proposed that the memory were only storage units based on their capacity. Later, Baddeley and Hitch, in 1974 , came up with the working memory model stating that short-term memory is not only a storage unit but also a form of an active process that is also a part of the storage unit (Baddeley \& Hitch, 1974). According to the model, a central executive is connected to two slave systems: the visuospatial sketch pad and the phonological loop. The phonological loop is the auditory domain of the working memory that contains the phonological store and articulatory process. Short-term memory has a limited capacity to temporarily hold information for $15-30 \mathrm{sec}$ with a capacity to memorize five to nine chunks (average seven).

Regarding the diurnal effects, literature mentions that memory recall can relatively change during the day, and changes in the circadian rhythm can affect memory recall capacities. Research papers by Anderson et al. (1991) and Baddeley et al. (1970) mentioned that shortterm memory and long-term memory have significant diurnal effects, with morning individuals performing better in the morning and evening individuals performing better in the evening. However, extensive research on diurnal effects and auditory working memory alone is required as auditory working memory is an essential component of speech perception and any diurnal effect might indicate an overall impact of speech perception during the day.

Working memory is a phenomenon that works as a catalyst in learning and academic performance (Alloway \& Alloway, 2010). As diurnal influence has been reported to affect the tasks that require mental efforts 
(Katzenberg et., 1998), there is a need to document the effects of time of the day on working memory. There is a dearth of literature related to the diurnal effect and auditory working memory. Several daily activities like vocal /instrumental music perception, comprehension of a spoken message, mental arithmetic etc., relies on working memory (Baddeley \& Hitch, 1974, Baddley et al., 1974, Baddeley et al., 1975, Cowan et al., 1997). Moreover, from a clinical and research point of view, working memory plays an important role in evaluating central auditory processing disorders (CAPD) (Nagaraj \& Magimairaj, 2020). For example, many of the test items in the CAPD test- battery utilizes auditory working memory capacity to yield the responses. Hence, exploring and ruling out the effect of diurnal changes over auditory working memory would enhance the reliability of results and aids in selecting a preferred time of the day for providing auditory training for individuals with CAPD. The current study investigates the effect of diurnal changes in the auditory working memory functions. The working memory scores and its reaction time in the domains of ascending span, descending span, digit forward, and digit backwards were compared between morning-, intermediate-, and evening-type individuals.

\subsection{MATERIALS AND METHODS}

\subsection{Ethical Considerations}

All the test procedures were explained to the participants, and informed consent was taken from all the participants and their parents. The test procedures were carried out using non-invasive techniques, and ethical clearance was obtained from the Ethical Approval committee of the Institute (AlISH/ERB/20202021/25).

\subsection{Subjects}

Thirty-two individuals were enrolled in the current study, out of which 11 were males, and 21 were females. The age range of the participants was 18 to 24 years, with a mean age of 21.6 years. None of the participants reported hearing loss or otological complaints like tinnitus, ear pain, ear discharge, and blocking sensations. The hearing sensitivity of the subjects was within the range of 15 decibels hearing levels for both air conduction and bone conduction thresholds and normal middle ear functioning, which was confirmed by conducting an immittance evaluation. Based on the Morningness - eveningness questionnaire by Horne \& Ostberg (1976), the participants were divided into moderate morning, moderate-evening and intermediate categories. Due to the limited availability of subjects, individuals falling under the definitely-morning and definitely-evening categories were excluded from the study.

\subsection{Procedures}

Air and bone conduction measurements of hearing thresholds were performed using the modified Hughson- Westlake procedure (Carhart \& Jerger, 1959). Air conductions measurements were done at octave frequencies $250 \mathrm{~Hz}$ to $8 \mathrm{kHz}$ using Telephonics TDH-39P supra-aural Headphones (Telephonics, Farmingdale, NY, USA) and bone conduction measurements at octaves ranging from $250 \mathrm{~Hz}$ to $4 \mathrm{kHz}$ using a Radioear $\mathrm{B} 71$ bone vibrator (Radioear, KIMMETRICS, Smithsburg, MD, USA) through an Inventis Piano dual-channel clinical audiometer (Inventis, 35127 Padova, ITALY). All the participants had their hearing thresholds within $15 \mathrm{dBHL}$ for air and bone conduction and an air-bone gap of $\leq 10$ decibels. Speech identification scores were measured using a Phonemically Balanced word list in Kannada, developed by Yathiraj and Vijayalakshmi (2005). Middle ear functioning was analyzed using a $226-\mathrm{Hz}$ probe tone, and ipsilateral and contralateral acoustic reflex thresholds were measured at 0.5, 1, 2 and $4 \mathrm{kHz}$ using a GSI tympstar middle ear analyzer (Grason Stadler Inc.GSI-61; Milford, NH, USA). All subjects had normal middle ear admittance and acoustic reflex thresholds were within normal sensation levels.

The subjects were divided into categories based on their scores obtained on administering the MorningnessEveningness - Questionnaire (Horne \& Ostberg, 1976). The questionnaire consisted of 19 questions that focused on an individual's preference and active time during the day that would be considered to be the best to carry out a mental or a physical task. Furthermore, it also evaluated sleep-wake patterns that an individual would follow, and the extend of tiredness or fatigue that one would have during a specific time of the day. Based on the scores, the subjects can be categorized into definitely morning (total scores 70-86), and moderately morning (total scores 59-69), definitely evening (total scores 16-30) and moderately evening (total scores 3141 ) and intermediate (total scores 42-58) categories. In the current study, only the subjects belonging to intermediate, moderately morning and moderate evening categories could be taken due to insufficient availability of subjects in 'definite' categories. 
The tests for auditory working memory were administered using Smriti-Shravan software. The software is a customized tool for the evaluation of auditory as well as visual working memory. The tests were administered by binaural presentation of a cluster of digits in the auditory module of the software. For the test of Forward Span, the subject must arrange the presented digits in forwarding span after each trial. The number of digits presented in each trial was dependent on the response of the client. Whenever the client gave a correct response, the number of digits presented in the upcoming trial increased and vice versa. Other tests carried out included tasks for arranging the digits in backward, ascending, and descending spans.

The instructions for the subjects were given orally as well as displayed on the screen before the commencement of each test. For Backward span testing, the subjects had to arrange the digits in reverse order at the end of the trial. Similarly, for Ascending and Descending spans, the digits had to be reordered in ascending and descending patterns. The test stimuli contained digits from 1 to 9 and were presented in English. After each test, the software calculated the respective scores and response times. The scores for each test were represented in Maximum value, which was the maximum length of the sequence arranged by the subject, and in the midpoint, which was the average of the responses of each task. For every test, the time taken to arrange the sequence in response to each trial was calculated and displayed as response time. All the subjects were tested between $8 \mathrm{am}$, and 9.30 am during the morning and between $5.30 \mathrm{pm}$ to $7.30 \mathrm{pm}$ during the evening, considering the convenient time for subjects. According to the questionnaire, this time range was chosen because the most active time of moderately morning and moderately evening individuals were between 8 am to 10 am and $5 \mathrm{pm}$ to $10 \mathrm{pm}$, respectively (Horne \& Ostberg, 1976). The order of individual tests was randomized among different subjects, and the sequence of time of the day was chosen randomly for every subject. The tests were conducted via calibrated audiometer at $40 \mathrm{~dB}$ SL (with speech recognition thresholds as reference). The midpoint, maximum value and response time for each test were noted and compared between the morning and evening.

\subsection{Statistical analyses}

The collected data were tabulated and statistically analyzed using SPSS version 25.0 (Frey, 2017). A Shapiro Wilk normality test was carried out to determine the normality of the data across the groups. Descriptive statistics were carried out to establish the mean, Standard Deviation (SD) and inter-quartile range. As there was a normal distribution based on the Shapiro Wilks test, a parametric paired t-test was carried out to establish the nature of significance between morning and evening under each category of individuals. The above-mentioned statistics were checked for the auditory working memory variables such as digit forward midpoint, digit forward maximum level, digit backward midpoint, digit backward maximum level, ascending digit span midpoint, ascending digit span maximum level, descending digit span midpoint, and descending digit span maximum level and reaction time of ascending, descending, forward, and backward.

\subsection{RESULTS}

Thirty-two individuals were separated into three groups based on the scores in their morningness-eveningness questionnaire (Horne \& Ostberg, 1976) as the moderate morning, intermediate, and moderate evening and auditory working memory tasks were done for all the subjects during morning and evening. A paired t-test was done for the auditory working memory tasks and their domains to establish the nature of significance between morning and evening. All three groups (moderate morning individuals, intermediate individuals, and moderate evening individuals) had normal auditory working memory scores in the digit span test with high scores in ascending and descending span test ranging from 8 to 9.2 in maximum scores and 5.6 to 7.4 in midpoint scores. This was followed by a forward span with maximum scores ranging from 6.9 to 7.4 and midpoint scores ranging from 5.6 to 6.2 .

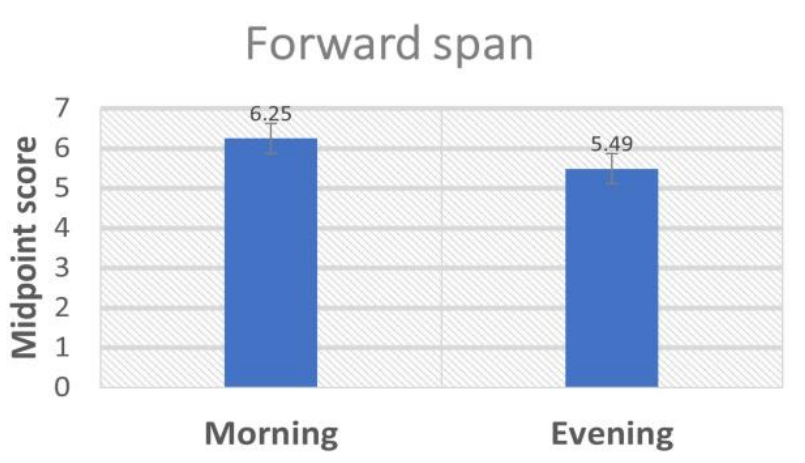

Time of the day

Figure 1: The figure illustrates a bar graph of the forward span scores for moderately morning individuals. 
Table 1: The descriptive statistics values of moderately morning category individuals across all 4 domains during the morning time and evening time of the day.

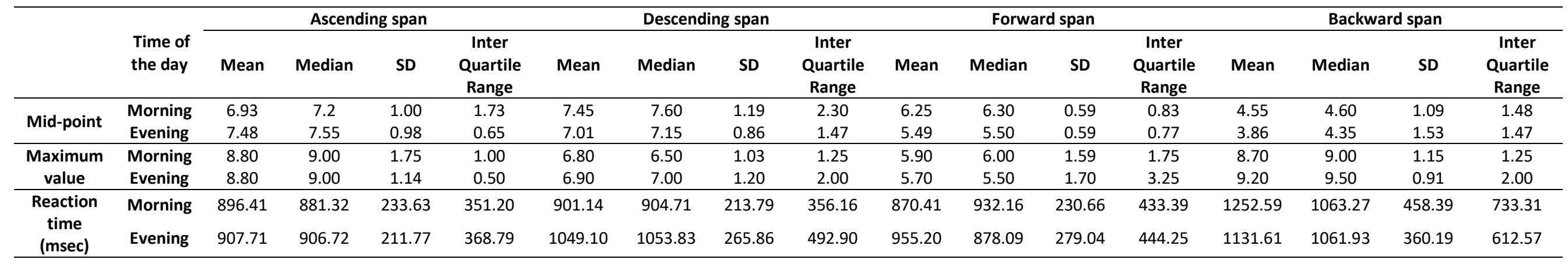

Table 2: The descriptive statistics values of intermediate category individuals across all 4 domains during the morning time and evening time of the day.

\begin{tabular}{|c|c|c|c|c|c|c|c|c|c|c|c|c|c|c|c|c|c|}
\hline & \multirow[b]{2}{*}{$\begin{array}{l}\text { Time of } \\
\text { the day }\end{array}$} & \multicolumn{4}{|c|}{ Ascending span } & \multicolumn{4}{|c|}{ Descending span } & \multicolumn{4}{|c|}{ Forward span } & \multicolumn{4}{|c|}{ Backward span } \\
\hline & & Mean & Median & SD & $\begin{array}{c}\text { Inter } \\
\text { Quartile } \\
\text { Range }\end{array}$ & Mean & Median & SD & $\begin{array}{l}\text { Inter } \\
\text { Quartile } \\
\text { Range }\end{array}$ & Mean & Median & SD & $\begin{array}{c}\text { Inter } \\
\text { Quartile } \\
\text { Range }\end{array}$ & Mean & Median & SD & $\begin{array}{c}\text { Inter } \\
\text { Quartile } \\
\text { Range }\end{array}$ \\
\hline \multirow{2}{*}{ Mid-point } & Morning & 7.2 & 7.15 & 0.65 & 1.25 & 7.12 & 7.6 & 1.09 & 1.35 & 6.03 & 5.55 & 1.1 & 1.67 & 4.51 & 4.5 & 1.2 & 1.58 \\
\hline & Evening & 7.38 & 7.6 & 0.99 & 0.95 & 6.9 & 7.4 & 1.59 & 1.2 & 5.54 & 5.7 & 0.9 & 1.85 & 4.22 & 3.8 & 1.01 & 1.95 \\
\hline \multirow{2}{*}{$\begin{array}{c}\text { Maximum } \\
\text { value }\end{array}$} & Morning & 8.3 & 8 & 1.05 & 1 & 8.2 & 9 & 1.54 & 1.5 & 7.7 & 8 & 1.41 & 3 & 5.7 & 6 & 1.05 & 1.5 \\
\hline & Evening & 8.6 & 9 & 1.26 & 1 & 8.4 & 8.5 & 1.07 & 1 & 7.1 & 7 & 0.87 & 2 & 5.6 & 6 & 1.71 & 2.25 \\
\hline $\begin{array}{l}\text { Reaction } \\
\text { time } \\
\text { (msec) }\end{array}$ & Morning & 858.67 & 973.55 & 267.12 & 525.5 & 1041.98 & 1139.14 & 284.41 & 399.17 & 1125.02 & 1042.3 & 399.37 & 591.94 & 1402.17 & 1321.24 & 346.98 & 626.64 \\
\hline
\end{tabular}

Table 3: The descriptive statistics values of moderately evening category individuals across all 4 domains during the morning time and evening time of the day.

\begin{tabular}{|c|c|c|c|c|c|c|c|c|c|c|c|c|c|c|c|c|c|}
\hline & \multirow[b]{2}{*}{$\begin{array}{l}\text { Time of } \\
\text { the day }\end{array}$} & \multicolumn{4}{|c|}{ Ascending span } & \multicolumn{4}{|c|}{ Descending span } & \multicolumn{4}{|c|}{ Forward span } & \multicolumn{4}{|c|}{ Backward span } \\
\hline & & Mean & Median & SD & $\begin{array}{c}\text { Inter } \\
\text { Quartile } \\
\text { Range }\end{array}$ & Mean & Median & SD & $\begin{array}{c}\text { Inter } \\
\text { Quartile } \\
\text { Range }\end{array}$ & Mean & Median & SD & $\begin{array}{c}\text { Inter } \\
\text { Quartile } \\
\text { Range }\end{array}$ & Mean & Median & SD & $\begin{array}{c}\text { Inter } \\
\text { Quartile } \\
\text { Range }\end{array}$ \\
\hline \multirow{2}{*}{ Mid-point } & Morning & 6.74 & 7.15 & 1.82 & 2.25 & 6.11 & 6.35 & 1.32 & 2.4 & 5.07 & 5.3 & 1.29 & 1.3 & 3.84 & 3.45 & 1.09 & 1.65 \\
\hline & Evening & 6.89 & 7.5 & 1.41 & 1.5 & 6.46 & 7.3 & 1.68 & 2.43 & 5.62 & 5.55 & 0.94 & 1.55 & 4.13 & 4.1 & 1.4 & 2.55 \\
\hline \multirow{2}{*}{$\begin{array}{c}\text { Maximum } \\
\text { value }\end{array}$} & Morning & 8.8 & 9 & 1.75 & 1 & 8.5 & 8.5 & 1.43 & 1.5 & 6.8 & 6.5 & 1.03 & 1.25 & 5.9 & 6 & 1.59 & 1.75 \\
\hline & Evening & 8.8 & 9 & 1.13 & 0.5 & 8 & 8.5 & 1.82 & 2.75 & 6.9 & 7 & 1.19 & 2 & 5.7 & 5.5 & 1.7 & 3.25 \\
\hline $\begin{array}{l}\text { Reaction } \\
\text { time } \\
\text { (msec) }\end{array}$ & Morning & 886.93 & 923.33 & 288.29 & 416.17 & 1151.08 & 1144.88 & 289.29 & 377.93 & 971.56 & 963.21 & 370.74 & 356.36 & 1049.81 & 1104.72 & 355.55 & 685.98 \\
\hline
\end{tabular}


The backward span, the most complex test, had the least scores, with maximum scores ranging from 5.7 to 6.4 and midpoint scores ranging from 4.1 to 4.5 . Similarly, the reaction time was higher for the backward span test when compared to the other tests. The mean, median, standard deviation and interquartile range of each task obtained for each category of individuals tested during morning and evening have been displayed in Tables 1, 2 and $\mathbf{3 .}$

With respect to the presence of significance, except the significance noticed in digit forward midpoint for moderately morning individuals between morning and evening $(p<0.05)$, there were no significant differences $(p>0,05)$ between morning and evening for all the parameters, including maximum values, midpoints, and reaction times of ascending, descending, forward and backward span tasks for all the three categories of individuals indicating no significant effect of diurnal changes on auditory working memory. The mean midpoint scores for forward span by moderately morning individuals have been depicted in figure 1 . The results of inferential statistics have been depicted in Tables 4, 5 and 6.

Table 4: Inferential statistics ( $\mathrm{t}$ and $p$ values) between the time of morning and evening in moderately morning category individuals.

\begin{tabular}{lccccccccc}
\hline & \multicolumn{2}{c}{ Ascending span } & \multicolumn{2}{c}{ Descending span } & \multicolumn{2}{c}{ Forward span } & \multicolumn{2}{c}{ Backward span } \\
\cline { 2 - 10 } & t value & $\boldsymbol{p}$ value & t value & $\boldsymbol{p}$ value & t value & $\boldsymbol{p}$ value & t value & $\boldsymbol{p}$ value \\
\hline Mid-point & -1.57 & 0.51 & 1.17 & 0.27 & 3.39 & $<0.01^{*}$ & 1.60 & 0.43 \\
Maximum value & -1.04 & 0.32 & -0.37 & 0.71 & 2.02 & 0.07 & 1.56 & 0.15 \\
Reaction time & -1.31 & 0.89 & -1.65 & 0.13 & -1.15 & 0.27 & 0.80 & 0.43 \\
\hline
\end{tabular}

* statistically significant

Table 5: Inferential statistics ( $\mathrm{t}$ and $p$ values) between the time of morning and evening in intermediate category individuals.

\begin{tabular}{lcccccccc}
\hline & \multicolumn{2}{c}{ Ascending span } & \multicolumn{2}{c}{ Descending span } & \multicolumn{2}{c}{ Forward span } & \multicolumn{2}{c}{ Backward span } \\
\cline { 2 - 10 } & $\mathbf{t}$ value & $\boldsymbol{p}$ value & $\mathbf{t}$ value & $\boldsymbol{p}$ value & $\mathbf{t}$ value & $\boldsymbol{p}$ value & $\mathbf{t}$ value & $\boldsymbol{p}$ value \\
\hline Mid-point & -0.59 & 0.56 & 0.39 & 0.70 & 1.43 & 0.18 & 0.64 & 0.53 \\
Maximum value & -0.89 & 0.39 & -0.55 & 0.39 & 1.32 & 0.21 & 0.31 & 0.75 \\
Reaction time & -1.47 & 0.17 & -0.80 & 0.44 & -0.69 & 0.50 & -0.19 & 0.38 \\
\hline
\end{tabular}

Table 6: Inferential statistics ( $\mathrm{t}$ and $p$ values) between the time of morning and evening in moderately evening category individuals.

\begin{tabular}{lcccccccc}
\hline & \multicolumn{2}{c}{ Ascending span } & \multicolumn{2}{c}{ Descending span } & \multicolumn{2}{c}{ Forward span } & \multicolumn{2}{c}{ Backward span } \\
\cline { 2 - 10 } & $\mathbf{t}$ value & $\boldsymbol{p}$ value & $\mathbf{t}$ value & $\boldsymbol{p}$ value & t value & $\boldsymbol{p}$ value & $\mathbf{t}$ value & $\boldsymbol{p}$ value \\
\hline Mid-point & -0.76 & 0.46 & -1.16 & 0.27 & -0.63 & 0.54 & -0.78 & 0.45 \\
Maximum value & 0.00 & 1.00 & 1.62 & 0.13 & -0.26 & 0.79 & 0.48 & 0.64 \\
Reaction time & -0.19 & 0.38 & 0.49 & 0.63 & 1.9 & 0.08 & 0.51 & 0.62 \\
\hline
\end{tabular}

\subsection{DISCUSSION}

The auditory working memory is a process of maintaining the sounds heard in mind for small time intervals when no other sound is present around. The time span it might last could be from a few seconds to a minute and it is a sensory memory that gets faded with the passage of time and overwritten with the arrival of a new stimulus. The neurological basis of working memory underlies complex structural and functional neural interlinkage throughout the auditory cortex and associated areas (Kumar et al., 2014). The human biological clock comprises a circadian pacemaker formed by the cells of SCN situated within the anterior portion of the hypothalamus. Even though there are a few inter and intra-individual changes, the time period of the human biological clock is $\sim 24$ hours. In order to 
maintain this 24-hour sleep/wake cycle, the circadian pacemaker has to adjust daily (Revell \& Eastman, 2005). The major input that feeds the SCN is the input picked up by the photoreceptors present in the retina as lights enter the eyes. The signal picked up by the retina is transmitted to the SCN via the retinohypothalamic tract and delivers the external input that helps to reset the biological clock mechanism.

Numerous physical and physiological processes like body temperature, blood pressure, secretion of hormones, cognitive tasks, and sleep/wake cycle have been extensively reported to be influenced by the circadian rhythms (Berson et al., 2002; Duffy \& Wright, 2005). The current study was an initial attempt to explore the diurnal influences on the auditory working memory. As previous literatures have reported significant diurnal changes on tasks that involved cognitive processes and focused attention, we were expecting a similar diurnal effect on auditory working memory. Surprisingly, our results revealed no statistically significant effect of morning or evening that influenced the tasks administered except one task in which the midpoint scores of forward span showed statistically significant better scores exhibited by morning-type individuals when tested during the morning. This is in agreement with the findings reported in studies on auditory temporal processing, which had shown significant diurnal effects (Nikhil et al., 2018; Prakash et al., 2021). Their studies revealed a better auditory temporal processing abilities during the morning for morning-type individuals, and similar improvements in scores were noted for evening-type individuals when tested during the evening. In the current study, since only one parameter of one task exhibited this diurnal effect, it remains questionable and requires additional evidence to validate this finding. However, the remaining test findings showed no significant diurnal effects in any of the working memory tasks assessed for the three categories of individuals both in their score values as well as in their response times. Similar findings were reported by Ezzatian et al., (2010), who studied diurnal effects on within-channel auditory gap detection, auditory channel capacity, and memory of spoken discourse, which revealed no significant changes noted between morning and evening test scores. Mackenzie (2000), who studied diurnal effects on screening tests for auditory processing found that the performance of the subjects was not significantly influenced by diurnal changes. Another study by Petros et al. (1990) stated that the difficulty of the task is a major factor that gets affected by diurnal changes. They conducted prose recall tasks which involved two easy and two difficult materials, conducted during different times of the day and found that the recall of the easy material was not significantly influenced by the time of the day. The recall of difficult material required higher sensory and cognitive involvement, which were found to be susceptible to diurnal changes.

According to a study conducted by Kumar et al. (2016), using $\mathrm{fMRI}$ in humans, reported that the neurophysiological mechanism that underlies the process of auditory working memory had numerous interconnections throughout the cortex. It was found that during the maintenance period of pure tone stimuli in mind, there was long-ranged connectivity of the auditory cortex with the hippocampus and inferior frontal gyrus. During the subvocal rehearsals, there was activation of the left inferior frontal gyrus. Functional connectivity of Heschl's gyrus and the right inferior frontal gyrus was observed in a study that assessed neurological bases of music perception(Albouy et al., 2013). To perceive constantly varying tonal patterns, which underlies the perception of sequential tones as in the case of music, the functional and structural interconnections of the auditory cortex and inferior and superior front gyri plays a key role.

One of the possible explanations for the lack of diurnal influences over auditory working memory could be the inhibitory control of an individual in carrying out a higher-order function like auditory working memory such that it is less susceptible to diurnal changes. Second, as mentioned by Kerkhof (1982), where the P450 amplitude showed no significant diurnal change due to the fluctuation in the processing of the different aspects of tasks performed, in our case, the auditory working memory may show different processing at the cortical level which does not involve any diurnal effects. Third, unlike other temporal resolution tasks which were performed in studies by Nikhil et al. (2018) and Prakash et al. (2021), during an ongoing trial in which digits are presented, the subvocal rehearsal performed by the subjects activates various regions of the frontal lobe and other associated structure which could possibly strengthen the maintenance of stimuli in mind and overcome the inhibitory controls linked with the time of the day (Kumar et al., 2016). Fourth, there could be an interplay of long-term memory and visual memory when using stimuli like digits which has got a 
defined semantic and graphical representation in an individual's inventory compared to tonal signals, which would enhance the encoding and maintenance of digits stimuli in the sensory memory (Visscher et al., 2007). All these assumptions point towards the auditory working memory to comparatively be a higher-order auditory function with numerous interlinkages with various areas of the nervous system, thus becoming less susceptible to diurnal changes. Another possibility would be the time of testing for the evening, which was around $7.30 \mathrm{pm}$ due to the convenient time of subjects. Extending the testing during the evening to 8 to $9 \mathrm{pm}$ might have shown even more significantly poorer scores in morning-type individuals and improved scores in evening-type individuals. Hence the current study reports a lack of diurnal effects in the auditory working memory of moderately-morning and moderatelyevening type individuals.

Due to the limited availability of subjects under definitely-morning and evening type categories, they were excluded from the study. As there are more chances for stronger diurnal effects to be present for definite morning and definite evening categories of individuals, studying auditory working memory on these individuals could possibly yield significant diurnal changes in working memory scores. This study was carried out in younger adults, and future research can be conducted on older adults.

\subsection{CONCLUSIONS}

The current study aimed to rule out diurnal effects in the auditory working memory of normally hearing younger adults. The tests were carried out by presenting a cluster of digits binaurally, and each task was to arrange them in forward, backward, ascending, and descending patterns. The results revealed no significant diurnal effects on scores and response times of auditory working memory tasks in all three categories of individuals. The stronger and multisite structural and functional neuroanatomical connections that underlie auditory working memory phenomenon could be the possible mechanism due to which there was no evidence of diurnal effects present in moderately morning and moderately evening category individuals.

Acknowledgements: The authors would acknowledge director Dr. M Pushpavathi, Director, All India Institute of Speech and Hearing, affiliated to the University of Mysore, for providing the platform for research and extend their gratitude to all the participants.

Author Contributions: PP*, AU, PP and CS conceived and designed the experiments, CS and PP performed the experiments, $\mathrm{AU}, \mathrm{PP}$ and $\mathrm{PP} *$ analysed the data, $\mathrm{PP} *$ contributed materials/analysis tools, PP, AU, CS and PP* wrote the paper.

Conflicts of Interest: The authors declare no conflict of interest.

\section{References}

Albouy, P., Mattout, J., Bouet, R., Maby, E., Sanchez, G., Aguera, P. E., Daligault, S., Delpuech, C., Bertrand, O., Caclin, A., \& Tillmann, B. (2013). Impaired pitch perception and memory in congenital amusia: The deficit starts in the auditory cortex. Brain, 136(5), 1639-1661. https://doi.org/10.1093/brain/awt082

Alloway, T. P., \& Alloway, R. G. (2010). Investigating the predictive roles of working memory and IQ in academic attainment. Journal of Experimental Child Psychology, 106(1), 20-29. https://doi.org/10.1016/j.jecp.2009.11.003

Alloway, T. P., Rajendran, G., \& Archibald, L. M. D. (2009). Working memory in children with developmental disorders. Journal of Learning Disabilities, 42(4), 372-382. https://doi.org/10.1177/0022219409335214

Anderson, M. J., Petros, T. V., Beckwith, B. E., Mitchell, W. W., \& Fritz, S. (1991). Individual Differences in the Effect of Time of Day on Long-Term Memory Access. The American Journal of Psychology, 104(2), 241. https://doi.org/10.2307/1423157

Baddeley, A. D., \& Hitch, G. (1974). Working memory. Psychology of Learning and Motivation - Advances in Research and Theory, 8(C), 47-89. https://doi.org/10.1016/S0079-7421(08)60452-1

Baddeley, A. D., Hatter, J. E., Scott, D., \& Snashall, A. (1970). Memory and Time of Day. Quarterly Journal of Experimental Psychology, 22(4), 605-609. https://doi.org/10.1080/14640747008401939

Baddeley, A. D., Thomson, N., \& Buchanan, M. (1975). Word length and the structure of short-term memory. Journal of Verbal Learning and Verbal Behavior, 14(6), 575-589. https://doi.org/10.1016/s0022-5371(75)80045-4

Berson, D. M., Dunn, F. A., \& Takao, M. (2002). Phototransduction by retinal ganglion cells that set the circadian clock. Science, 295(5557), 1070-1073. https://doi.org/10.1126/science.1067262

Carhart, R., \& Jerger, J. F. (1959). Preferred method for clinical determination of pure-tone thresholds. Journal of Speech and Hearing Disorders, 24(4), 330-345. https://doi.org/10.1044/jshd.2404.330 
Cowan, N., Wood, N. L., Nugent, L. D., \& Treisman, M. (1997). There Are Two Word-Length Effects in Verbal Short-Term Memory: Opposed Effects of Duration and Complexity. Psychological Science, 8(4), 290-295. https://doi.org/10.1111/j.1467-9280.1997.tb00440.x

Duffy, J. F., \& Wright, K. P. (2005). Entrainment of the human circadian system by light. Journal of Biological Rhythms, 20(4), 326-338. https://doi.org/10.1177/0748730405277983

Ezzatian, P., Pichora-Fuller, M. K., \& Schneider, B. A. (2010). Do Circadian Rhythms Affect Adult Age-Related Differences in Auditory Performance? Canadian Journal on Aging / La Revue Canadienne Du Vieillissement, 29(2), $215-221$. https://doi.org/10.1017/s0714980810000139

Frey, F. (2017). SPSS (Software) . The International Encyclopedia of Communication Research Methods, 1-2. https://doi.org/10.1002/9781118901731.iecrm0237

Horne, J. A., \& Ostberg, O. (1976). A self assessment questionnaire to determine Morningness Eveningness in human circadian rhythms. International Journal of Chronobiology, 4(2), 97-110. http://europepmc.org/abstract/med/1027738\%0Apapers3://publication/uuid/F0AE4A5C-52EA-432A-AFDB2C905277F3E1

Huang, J., Katsuura, T., Shimomura, Y., \& Iwanaga, K. (2005). Diurnal Changes of Human Cognitive Function in Response to Sound Stimuli of Different Frequencies for Evening-Type Subjects. Journal of the Human-Environment System, 8(1), 712. https://doi.org/10.1618/jhes.8.7

Katzenberg, D., Young, T., Finn, L., Lin, L., King, D. P., Takahashi, J. S., \& Mignot, E. (1998). A CLOCK polymorphism associated with human diurnal preference. Sleep, 21(6), 569-576. https://doi.org/10.1093/sleep/21.6.569

Kerkhof, G. A., Korving, H. J., Geest, H. M. M. W. v.d., \& Rietveld, W. J. (1980). Diurnal differences between morning-type and evening-type subjects in self-rated alertness, body temperature and the visual and auditory evoked potential. Neuroscience Letters, 16(1), 11-15. https://doi.org/10.1016/0304-3940(80)90093-2

Kerkhof, G. A. (1982). Event-Related Potentials and Auditory Signal Detection: Their Diurnal Variation for Morning-Type and Evening-Type Subjects. Psychophysiology, 19(1), 94-103. https://doi.org/10.1111/j.1469-8986.1982.tb02607.x

Kerkhof, G. A. (1985). Inter-individual differences in the human circadian system: A review. Biological Psychology, 20(2), 83112. https://doi.org/10.1016/0301-0511(85)90019-5

Kumar, S., Bonnici, H. M., Teki, S., Agus, T. R., Pressnitzer, D., Maguire, E. A., \& Griffiths, T. D. (2014). Representations of specific acoustic patterns in the auditory cortex and hippocampus. Proceedings of the Royal Society B: Biological Sciences, 281(1791). https://doi.org/10.1098/rspb.2014.1000

Kumar, S., Joseph, S., Gander, P. E., Barascud, N., Halpern, A. R., \& Griffiths, T. D. (2016). A brain system for auditory working memory. Journal of Neuroscience, 36(16), 4492-4505. https://doi.org/10.1523/JNEUROSCl.4341-14.2016

MacKenzie, C. (2000). Time of Day Effects on the Performance on the Screening Test of Auditory Processing. Theses and Dissertations. https://commons.und.edu/theses/973

Nagaraj, N. K., \& Magimairaj, B. M. (2020). Auditory processing in children: Role of working memory and lexical ability in auditory closure. PLOS ONE, 15(11), e0240534. https://doi.org/10.1371/journal.pone.0240534

Nikhil, J., Megha, K. N., \& Prabhu, P. (2018). Diurnal changes in differential sensitivity and temporal resolution in morningtype and evening-type individuals with normal hearing. World Journal of Otorhinolaryngology - Head and Neck Surgery, 4(4), 229-233. https://doi.org/10.1016/j.wjorl.2017.10.001

Petros, T. V., Beckwith, B. E., \& Anderson, M. (1990). Individual differences in the effects of time of day and passage difficulty on prose memory in adults. British Journal of Psychology, 81(1), 63-72. https://doi.org/10.1111/j.20448295.1990.tb02346.x

Prakash, P., Jayan, A., \& Prabhu, P. (2021). Effects of diurnal changes on temporal processing in morning-type and eveningtype individuals with normal hearing. European Archives of Oto-Rhino-Laryngology, 278, 3073-3079. https://doi.org/10.1007/s00405-021-06605-y

Revell, V. L., \& Eastman, C. I. (2005). How to trick mother nature into letting you fly around or stay up all night. Journal of Biological Rhythms, 20(4), 353-365. https://doi.org/10.1177/0748730405277233

Schmidt, C., Collette, F., Cajochen, C., \& Peigneux, P. (2007). A time to think: Circadian rhythms in human cognition. Cognitive Neuropsychology, 24(7), 755-789. https://doi.org/10.1080/02643290701754158

Visscher, K. M., Kaplan, E., Kahana, M. J., \& Sekuler, R. (2007). Auditory short-term memory behaves like visual short-term memory. PLoS Biology, 5(3), 0662-0672. https://doi.org/10.1371/journal.pbio.0050056

Vuontela, V., Steenari, M. R., Carlson, S., Koivisto, J., Fjällberg, M., \& Aronen, E. T. (2003). Audiospatial and visuospatial working memory in 6-13 year old school children. Learning and Memory, 10(1), 74-81. https://doi.org/10.1101//m.53503

Yathiraj, A., \& Vijayalakshmi, C. S. (2005). Phonemically balanced word list in Kannada: developed in department of audiology. Mysore: AlISH. http://aiish.ac.in/images/pdf/08-09aud.pdf 